\title{
Use of $25 \%$ sulfur hexafluoride gas mixture may minimize short-term postoperative hypotony in sutureless 25 -gauge pars plana vitrectomy surgery
}

This article was published in the following Dove Press journal:

Clinical Ophthalmology

27 February 2013

Number of times this article has been viewed

\section{Yoreh Barak \\ James W Heroman \\ Shlomit Schaal}

Department of Ophthalmology and Visual Sciences, University of Louisville, Louisville, KY, USA
Correspondence: Shlomit Schaal 30IE Muhammad Ali Blvd, Louisville, KY 40202, USA

Tel +I 50275 | 4379

Fax +I 5028522737

Emails.schaal@louisville.edu
Background: The purpose of this study was to compare postoperative intraocular pressures and percentage of vitreous cavity gas fill one day following 25-gauge pars plana vitrectomy with $20 \%$ versus $25 \%$ sulfur hexafluoride $\left(\mathrm{SF}_{6}\right)$ gas fill.

Methods: This was a retrospective review of 187 consecutive cases of 25 -gauge pars plana vitrectomy with complete fluid/gas exchange. The main outcome measures included percentage of gas fill of the vitreous cavity and intraocular pressure on postoperative day one.

Results: Fifty eyes underwent 25 -gauge pars plana vitrectomy with $20 \% \mathrm{SF}_{6}$ tamponade and 137 with $25 \% \mathrm{SF}_{6}$ tamponade. On postoperative day one in the $20 \% \mathrm{SF}_{6}$ group, there were five $(10 \%)$ patients with hypotony (intraocular pressure $\leq 5 \mathrm{mmHg}$ ) and none in the $25 \% \mathrm{SF}_{6}$ group. Mean intraocular pressure was $9 \pm 2.5 \mathrm{mmHg}$ and $16.8 \pm 2.4 \mathrm{mmHg}$ for the $20 \% \mathrm{SF}_{6}$ and $25 \% \mathrm{SF}_{6}$ groups, respectively $(P<0.01)$. None of the patients had postoperative intraocular pressure $>23 \mathrm{mmHg}$. Mean vitreous cavity gas fill on postoperative day one was $70.7 \% \pm 10 \%$ in the $20 \% \mathrm{SF}_{6}$ group and $89.5 \% \pm 2.2 \%$ in the $25 \% \mathrm{SF}_{6}$ group $(P<0.01)$. There was no difference in the number of phakic patients needing cataract surgery between the groups.

Conclusion: A slightly expansile concentration of $25 \% \mathrm{SF}_{6}$ gas can be safely and beneficially used in 25-gauge vitrectomy surgery to increase the amount of gas fill in the vitreous cavity and prevent postoperative hypotony.

Keywords: hypotony, 25-gauge pars plana vitrectomy, sulfur hexafluoride

\section{Introduction}

Small incision sutureless pars plana vitrectomy techniques have dramatically changed the field of retinal surgery. A rapid increase in indications for small incision vitrectomy has been evident in recent years. The main advantages of 25 -gauge pars plana vitrectomy incisions, when compared with standard 20-gauge sclerotomies, are faster wound healing, diminished conjunctival scarring, improved patient comfort, decreased postoperative inflammation, and shortened surgical time. ${ }^{1-4}$ However, the sutureless aspect of the technique has unique risks, including wound leak, hypotony, less than adequate gas bubble size, and increased rate of endophthalmitis. ${ }^{5-7}$ Further, postoperative hypotony, defined as intraocular pressure $\leq 5 \mathrm{mmHg}$, may lead to postoperative bleeding in diabetic patients as well as to choroidal and ciliochoroidal detachment, ${ }^{8}$ and may also explain the higher rate of endophthalmitis reported with perpendicular sclerotomies used in earlier small incision surgeries. Beveled incisions and newer vitrectomy systems have been introduced in an attempt to reduce the risk of postoperative hypotony and related complications. These have lowered the risk of hypotony, and may account for recent reports that small incision postoperative endophthalmitis rates are 
currently low $(0.02 \%)$ and comparable with endophthalmitis rates following 20-gauge vitrectomy. ${ }^{9-11}$ However, hypotony remains a frequent complication following 25 -gauge vitrectomy surgery. Bamonte et al recently reported the appearance of hypotony on postoperative day one following 25-gauge vitrectomy to be as high as $13.1 \% .^{12}$

Gas mixtures are often used in vitrectomy surgery to tamponade the retina. In 1973, Norton proposed the use of sulfur hexafluoride $\left(\mathrm{SF}_{6}\right)$ gas to provide a longer-acting gas bubble for intraocular tamponade. ${ }^{13}$ The nonexpansile concentration of $\mathrm{SF}_{6}$ is reported to be $20 \% .^{14}$

Because of potential sclerotomy leak, along with the possibility of decreased intraocular pressure and incomplete vitreous cavity fill after 25-gauge pars plana vitrectomy surgery, in this study we investigated whether the use of a slightly expansile concentration of $\mathrm{SF}_{6}$ would achieve a better postoperative gas fill and decrease the occurrence of postoperative hypotony.

\section{Materials and methods}

This study was approved by the institutional board review of the University of Louisville, KY, USA. Clinical charts of all consecutive patients who underwent 25-gauge pars plana vitrectomy by three surgeons (HK, TT, SS) with complete fluid/gas exchange at the University of Louisville from August 1, 2008, to May 1, 2010 were included. Clinical charts were reviewed, and patients were divided retrospectively into two groups according to whether $20 \%$ or $25 \% \mathrm{SF}_{6}$ gas was used as an internal tamponade at the conclusion of surgery. One surgeon (SS) used only $25 \% \mathrm{SF}_{6}$ gas and two surgeons used $20 \% \mathrm{SF}_{6}$ gas (HK, TT). Table 1 outlines the presurgical diagnoses. Data collection included patient age, indication for surgery, lens status, and intraocular pressure on postoperative day one using a tonopen (Tono-Pen AVIA tonometer, Reichert

Table I Diagnoses and clinical data

\begin{tabular}{|c|c|c|c|}
\hline & $20 \% \mathrm{SF}_{6}$ & $25 \% \mathrm{SF}_{6}$ & Total \\
\hline Number of patients & 50 & 137 & 187 \\
\hline \multicolumn{4}{|l|}{ Eye } \\
\hline Right & 31 & 75 & 106 \\
\hline Left & 19 & 62 & 81 \\
\hline \multicolumn{4}{|l|}{ Diagnosis } \\
\hline RRD* & 38 & 73 & III \\
\hline Macular hole & 9 & 22 & 31 \\
\hline ERM** & 2 & 19 & 21 \\
\hline Other & I & 23 & 24 \\
\hline \multicolumn{4}{|l|}{ Lens status } \\
\hline Phakic & 25 & 49 & 74 \\
\hline Pseudo-phakic & 25 & 88 & 113 \\
\hline
\end{tabular}

Notes: *Rhegmatogenous retinal detachment; **epiretinal membrane.
Technologies, NY, USA). If the intraocular pressure was lower than $6 \mathrm{mmHg}$ or higher than $25 \mathrm{mmHg}$, it was measured again using Goldmann applanation tonometry. The amount of gas fill in the vitreous cavity on postoperative day one was assessed by the attending retinal specialist, and patients were instructed to maintain a face-down position for a week. Safety data included the incidence of wound leak needing suture placement at the time of surgery, and formation of cataract requiring surgical extraction during the follow-up period of one year. Patients younger than 18 years, those who did not complete the follow-up period, those who did not undergo ocular examination on postoperative day one, and those who had trauma to their eye in the first 24 hours after surgery were excluded.

All patients underwent three-port pars plana vitrectomy (Accurus, Alcon Laboratories Inc, Fort Worth, TX, USA) under general or local anesthesia, depending on patient and surgeon preference. The conjunctiva and Tenon's capsule were displaced away from the intended sclerotomy site using forceps or a cotton swab. All incisions were created in an oblique (beveled, angled) fashion 3.5-4 mm posterior to the limbus in pseudophakic and phakic patients, respectively. Once past the trocar sleeve, the angle was set perpendicular to the ocular surface and the cannula was inserted further into the eye. At the conclusion of surgery, all patients had complete fluid-air exchange using a soft tip instrument simultaneously with gas injection through the infusion cannula. The cannula was then extruded from the eye, the sclerotomy site was gently rubbed with a wet Q-tip, and the sclerotomy was assessed for gas leak by wetting with balanced salt solution. Leaking sclerotomies were sutured. The statistical analysis was carried out using the Statistical Package for Social Sciences software version 17.0 (SPSS Inc, Chicago, IL, USA). The statistical analysis was performed using oneway analysis of variance. $P<0.05$ was accepted as being statistically significant.

\section{Results}

One hundred and eighty-seven patients who underwent 25 -gauge pars plana vitrectomy surgery consecutively at the University of Louisville met our inclusion criteria. At the end of surgery, 50 patients had $20 \% \mathrm{SF}_{6}$ as internal tamponade and 137 patients had the $25 \% \mathrm{SF}_{6}$ gas mixture. Presurgical diagnoses and clinical data for the groups are summarized in Table 1.

Five $(10 \%)$ patients were diagnosed with hypotony (intraocular pressure $\leq 5 \mathrm{mmHg}$ ) on postoperative day one in the $20 \% \mathrm{SF}_{6}$ group and none in the $25 \% \mathrm{SF}_{6}$ group. Mean 


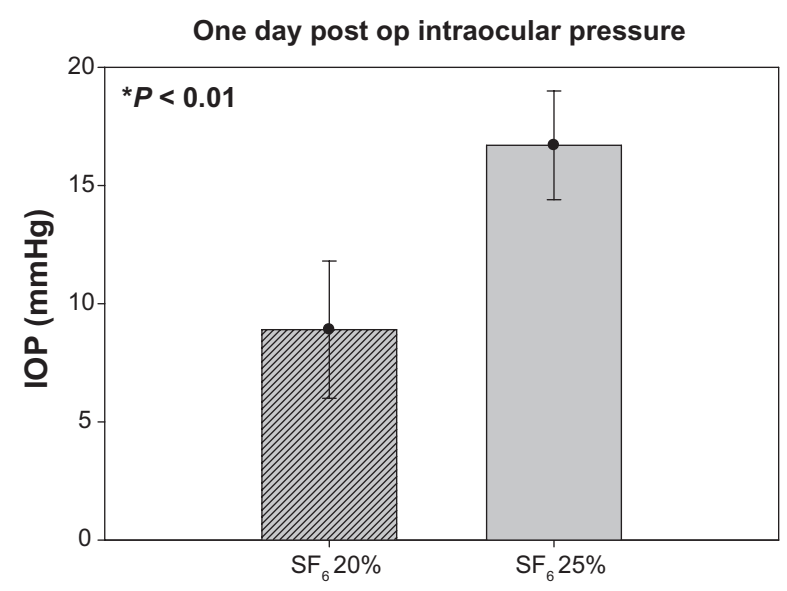

Figure I Intraocular pressure $(\mathrm{mmHg})$ measured on postoperative day one.

intraocular pressure (Figure 1) was $9 \pm 2.5(6-19) \mathrm{mmHg}$ for the $20 \% \mathrm{SF}_{6}$ group and $16.8 \pm 2.4(12-23) \mathrm{mmHg}$ for the $25 \% \mathrm{SF}_{6}$ group $(P<0.01)$. No patient in either group suffered from high postoperative intraocular pressure requiring medication. Mean vitreous cavity gas fill (Figure 2) was $70.7 \% \pm 10 \%$ and $89.5 \% \pm 2.2 \%$ in the $20 \% \mathrm{SF}_{6}$ and $25 \% \mathrm{SF}_{6}$ groups, respectively $(P<0.01)$. The frequency of sclerotomies needing suturing was low. There were three leaking sclerotomies requiring suturing in the $\mathrm{SF}_{6} 20 \%$ tamponade group and none in the $\mathrm{SF}_{6} 25 \%$ tamponade group. Three phakic patients (12\%) needed cataract surgery during the one-year follow-up in the $20 \% \mathrm{SF}_{6}$ group and seven (14\%) in the $25 \% \mathrm{SF}_{6}$ group. This difference was not statistically significant (Table 2).

\section{Discussion}

Pure $\mathrm{SF}_{6}$ gas expands to 1.9-2.0 times its original size because oxygen and nitrogen from the blood enter the gas bubble more rapidly than $\mathrm{SF}_{6}$ can leave the bubble. The most

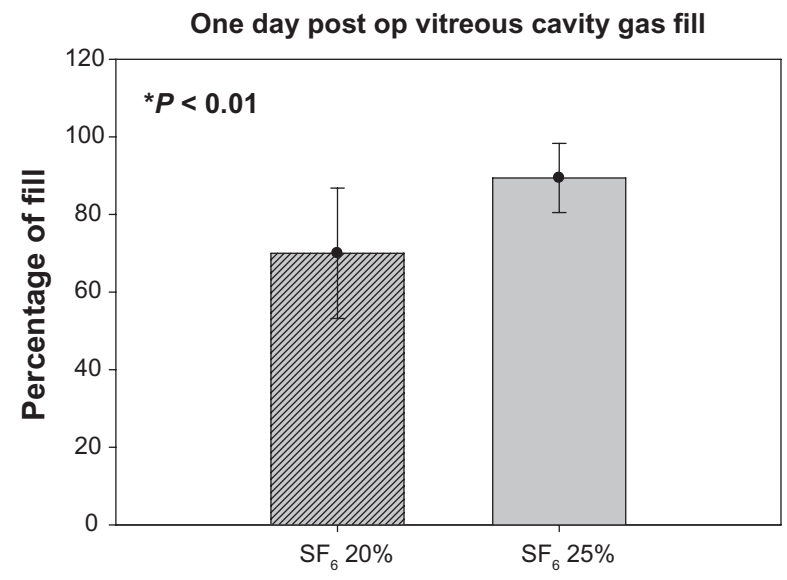

Figure 2 Percentage of gas fill of the vitreous cavity on postoperative day one.
Table 2 Phakic patients requiring cataract extraction within a year $(P=0.23)$

\begin{tabular}{lll}
\hline & $\begin{array}{l}\text { Number of } \\
\text { phakic patients }\end{array}$ & $\begin{array}{l}\text { Needed } \\
\text { cataract surgery }\end{array}$ \\
\hline $20 \% \mathrm{SF}_{6}$ & 25 & 3 \\
$25 \% \mathrm{SF}_{6}$ & 49 & 7 \\
\hline
\end{tabular}

rapid expansion occurs over the first 6-8 hours, and maximal expansion is reached at around 24 hours. $\mathrm{SF}_{6}$ lasts in the eye for 10-14 days. ${ }^{14}$ As mentioned earlier, the nonexpansile concentration of $\mathrm{SF}_{6}$ is $20 \% .{ }^{14}$ If the concentration of gas is greater than $20 \%$, a portion of the gas equal to the difference in the concentration will expand 1.9-2.0 times. We used 25\% $\mathrm{SF}_{6}$, so $5 \%$ of the gas could double in size. Assuming the volume of the vitreous cavity is $4 \mathrm{~mL},{ }^{14} 0.2 \mathrm{~mL}$ of the gas bubble doubles in size, resulting in an extra $0.2 \mathrm{~mL}$ of gas in the vitreous cavity during the first 24 hours after surgery. Tamponade with a slightly expansile concentration of $25 \%$ $\mathrm{SF}_{6}$ is ideal to prevent hypotony following sutureless small incision vitrectomy surgery. Even if some gas is lost through the sclerotomy in the immediate postoperative period, a portion of the gas bubble expands to keep the vitreous cavity full and normotonic.

Use of this slightly expansile concentration of gas as tamponade at the conclusion of 25-gauge pars plana vitrectomy surgery resulted in a statistically significant difference in intraocular pressure between the treatment groups on postoperative day one, and in the amount of gas present in the vitreous cavity. There were no cases of hypotony ( $\leq 5 \mathrm{mmHg}$ ) recorded in the group of patients receiving $25 \% \mathrm{SF}_{6}$ compared with five cases (10\%) in the group receiving $20 \% \mathrm{SF}_{6}$. No patient developed postoperative endophthalmitis.

Use of $25 \% \mathrm{SF}_{6}$ gas can prevent postoperative hypotony effectively in 25-gauge vitrectomies. A recent report by Kusuhara et al shows that leakage and hypotony remain a significant complication requiring frequent suturing of the sclerotomy in 23-gauge pars plana vitrectomy even with $25 \% \mathrm{SF}_{6}{ }^{15}$ Our different results using the 25 -gauge system may stem from the different technique used, ie, introducing a trocar, but it is more likely that the $10 \%$ leak reported by Kusuhara et al was secondary to the $20 \%$ larger diameter of the 23 -gauge trocar compared with the 25 -gauge one $(0.573 \mathrm{~mm}$ versus $0.455 \mathrm{~mm}$ ). Hsu et $\mathrm{al}^{10}$ reported a $1.8 \%-10 \%$ rate of postoperative hypotony after 25 -gauge vitrectomy, depending on the technique used for trocar insertion. We believe that hypotony, a potentially blinding complication of 25-gauge vitrectomy surgery, can be eliminated by combination of an 
oblique trocar insertion technique with infusion of $25 \% \mathrm{SF}_{6}$ gas at the conclusion of surgery.

One common complication of vitrectomy surgery with the use of intraocular gas bubbles is cataract formation. Surgical removal of the vitreous body leads to accelerated formation of nuclear sclerotic cataracts. ${ }^{16,17}$ In a group of patients older than 50 years, 79\% developed significant lens opacity in the surgical eye within 24 months. ${ }^{18}$ In the present study, the increased size of the gas bubble in the vitreous cavity did not cause a significant increase in cataract formation requiring extraction in the $25 \% \mathrm{SF}_{6}$ group during the follow-up period (up to 24 months), and there was no difference in the rate of cataract extraction between the groups. Despite the expansile intraocular gas concentration in the $25 \% \mathrm{SF}_{6}$ group, no excessive leak requiring suturing was noted, and the higher average intraocular pressure $16.8 \mathrm{mmHg}$ (range $12-23 \mathrm{mmHg}$ ) was well tolerated. None of the patients in this study suffered from high postoperative intraocular pressure requiring medication.

This retrospective research has some inherent limitations. One is that estimation of the amount of gas fill is a subjective measure, and can vary from observer to observer. However, there was still a statistically significant difference in the amount of gas fill between patients receiving 20\% and $25 \%$ $\mathrm{SF}_{6}$ gas mixtures, and objective intraocular pressure measurement helps to confirm that the vitreous cavity is indeed more filled with gas. The advantages of this concentration of $\mathrm{SF}_{6}$ gas in preventing hypotony after sutureless vitrectomy should be investigated further in prospective studies.

In conclusion, a slightly expansile concentration of $25 \% \mathrm{SF}_{6}$ can be used safely and beneficially in 25-gauge pars plana vitrectomy to increase the amount of gas fill in the vitreous cavity and to prevent postoperative hypotony and its related complications. This concentration should be considered routinely at the conclusion of 25-gauge pars plana vitrectomy.

\section{Acknowledgments}

The work was supported in part by an unrestricted grant from Research to Prevent Blindness Inc, New York, NY. The authors would like to thank Tongalp H Tezel and Henry J Kaplan, whose patients were included in this study.

Clinical Ophthalmology

\section{Publish your work in this journal}

Clinical Ophthalmology is an international, peer-reviewed journal covering all subspecialties within ophthalmology. Key topics include: Optometry; Visual science; Pharmacology and drug therapy in eye diseases; Basic Sciences; Primary and Secondary eye care; Patient Safety and Quality of Care Improvements. This journal is indexed on Submit your manuscript here: http://www.dovepress.com/clinical-ophthalmology-journal

\section{Disclosure}

The authors report no conflicts of interest in this work.

\section{References}

1. Chen E. 25-Gauge transconjunctival sutureless vitrectomy. Curr Opin Ophthalmol. 2007;18:188-193.

2. Fujii GY, De Juan E Jr, Humayun MS, et al. Initial experience using the transconjunctival sutureless vitrectomy system for vitreoretinal surgery. Ophthalmology. 2002;109:1814-1820.

3. Ibarra MS, Hermel M, Prenner JL, Hassan TS. Longer-term outcomes of transconjunctival sutureless 25 -gauge vitrectomy. Am J Ophthalmol. 2005;139:831-836.

4. Lakhanpal RR, Humayun MS, De Juan E Jr, et al. Outcomes of 140 consecutive cases of 25-gauge transconjunctival surgery for posterior segment disease. Ophthalmology. 2005;112:817-824.

5. Gupta OP, Weichel ED, Regillo CD, et al. Postoperative complications associated with 25-gauge pars plana vitrectomy. Ophthalmic Surg Lasers Imaging. 2007;38:270-275.

6. Kunimoto DY, Kaiser RS. Incidence of endophthalmitis after 20- and 25-gauge vitrectomy. Ophthalmology. 2007;114:2133-2137.

7. Schadlu R, Shah GK. Early postoperative intraocular pressure after 23-gauge sutureless small-incision pars plana vitrectomy. Retina. 2009;29:1043-1044.

8. Yamane S, Inoue M, Arakawa A, Kadonosono K. Early postoperative hypotony and ciliochoroidal detachment after microincision vitrectomy surgery. Am J Ophthalmol. 2012;153:1099-1103.

9. Bahrani HM, Fazelat AA, Thomas M, et al. Endophthalmitis in the era of small gauge transconjunctival sutureless vitrectomy - meta analysis and review of literature. Semin Ophthalmol. 2010;25:275-282.

10. Hsu J, Chen E, Gupta O, Fineman MS, Garg SJ, Regillo CD. Hypotony after 25-gauge vitrectomy using oblique versus direct cannula insertions in fluid-filled eyes. Retina. 2008;28:937-940.

11. Wu L, Berrocal MH, Arevalo JF, et al. Endophthalmitis after pars plana vitrectomy: results of the Pan American Collaborative Retina Study Group. Retina. 2011;31:673-678.

12. Bamonte G, Mura M, Stevie TH. Hypotony after 25-gauge vitrectomy. Am J Ophthalmol. 2011;151:156-160.

13. Norton EW. Intraocular gas in the management of selected retinal detachments. Trans Am Acad Ophthalmol Otolaryngol. 1973;77: OP85-OP98.

14. Ryan SJ, Schachat AP. Retina. Philadelphia, PA: Elsevier Mosby; 2005.

15. Kusuhara $\mathrm{S}$, Ooto $\mathrm{S}$, Kimura $\mathrm{D}$, et al. Intraocular gas dynamics after 20 -gauge and 23-gauge vitrectomy with sulfur hexafluoride gas tamponade. Retina. 2011;31:250-256.

16. Holekamp NM, Shui YB, Beebe DC. Vitrectomy surgery increases oxygen exposure to the lens: a possible mechanism for nuclear cataract formation. Am J Ophthalmol. 2005;139:302-310.

17. Schaal S, Beiran I, Rubinstein I, Miller B, Dovrat A. Lenticular oxygen toxicity. Invest Ophthalmol Vis Sci. 2003;44:3476-3484.

18. Melberg NS, Thomas MA. Nuclear sclerotic cataract after vitrectomy in patients younger than 50 years of age. Ophthalmology. 1995;102: $1466-1471$.

PubMed Central and CAS, and is the official journal of The Society of Clinical Ophthalmology (SCO). The manuscript management system is completely online and includes a very quick and fair peer-review system, which is all easy to use. Visit http://www.dovepress.com/ testimonials.php to read real quotes from published authors. 